\title{
Example of A Kinetic Mathematical Modeling in Food Engineering
}

\author{
Özlem ERTEKİN ${ }^{1, *}$ \\ ${ }^{1}$ Department of Food Engineering, Munzur University, Tunceli, Turkey
}

\begin{abstract}
Mathematical modeling of biochemical, chemical reaction processes facilitates understanding. The kinetics of these reaction processes can be analyzed mathematically and kinetics are presented as systems of differential equations. Mathematical model of a reaction kinetic is studied in this study. Bernoulli-Sub equation function method is used in this study. This example can be new model for food engineering applications.
\end{abstract}

\section{Introduction}

Reaction kinetic is a science that examines the fast and mechanisms of reactions. Mechanism of reaction is defined as the detailed description of the reaction based on the behavior of atoms, molecules and ions. Many reactions occur with mechanisms involving multiple steps. Various chemical or biochemical reactions occur during the processing and storage of food. Food quality can be lost with these reactions. The aim is to obtain the good quality product by ensuring these reactions at the lowest level. Knowledge the rate and mechanism of reactions allows for the preparation of the good condution in performing any food process and establishment of storage conditions [1].

About a mathematical reference on chemical kinetics see, for instance, [2] and for food reaction technology reference see, for example, [3]. About references on mathematical models, see $[4,5,6]$.

According to [7] mathematical modeling is used in cases where experimental studies are limited or impossible. Mathematical modeling has widely potential for application in food processing research and food industry in Turkey. According to another explanation, the expression of models inactivation of microorganisms in food is important because these models allow later estimation in similar cases without experiment [8].

Mathematical modeling can be used in areas different food engineering such as food chemistry, food microbiology, food processing. Recently, some scientists have focused on food engineering in mathematical modeling. For example, quality properties of traditional fermented sausage including total mesophilic aerobic bacteria, lactic acid bacteria, total Enterobacteriaceae and Staphylococcus/Micrococcus counts and other quality features were studied during storage duration, and kinetic model estimation for the changes in these quality characteristics were applied [9].

Moreover, nowadays mathematical modeling is essential to determine the growth kinetics of microorganisms and it is significant that can determine the temperature the relationship in perishable foods.

There are many different models used to symbolize from various real world problems to specific case studies $[10,11,15]$.

\footnotetext{
*Corresponding author: oertekin@munzur.edu.tr
} 
This report is arranged as follows: In section 2, we describe the Bernoulli SubEquation function method (BSEFM), In section 3, we consider the following kinetic model defined as

$$
\frac{d[B]}{d t}=k_{+}[A][B]-k_{-}[B]^{2},
$$

where $[A]$ is concentration and $[B]$ is concentration, $k$ is the rate constant, $k_{+}$is forward side, $k_{-}$is back side, $\mathrm{t}$ is time [12].

Moreover, for simplicity, we can rewrite Eq.(1a) as following

$$
\frac{d U}{d t}=C U-P U^{2}
$$

where $U=[B]$, is dependent variable, $C=k_{+}[A]$ and $P=k_{-}$are real constants with non- zero.

We apply the tool to the model which ordinary differential equation. Finally, we introduce a general conclusion about the results obtained by BSEFM in section 4 .

\section{Fundamental Properties of Bernoulli-Sub-Equation Function}

\section{Method}

An approach to the mathematical models including partial differential equations will be exhibited in this sub- section of study. The steps of the this technique can be taken as below $[13,14]$.

Step 1: We theorize the partial differential equation in two variables such as $\mathrm{x}, \mathrm{t}$ and a dependent variable $u$;

$$
\mathrm{P}\left(u_{x}, u_{t}, u_{x x}, u_{x t} \ldots\right)=0
$$

and take the wave transformation

$$
u(x, t)=U(\eta), \eta=x-c t,
$$

where $\mathrm{c} \nsubseteq 0$. Substituting Eq.(3) into Eq.(2), it gives us the following nonlinear ordinary differential equation;

$$
N\left(U, U^{\prime}, U^{\prime \prime}, U^{\prime \prime \prime}, \ldots\right)=0,
$$

where $U=U(\eta), U^{\prime}=\frac{d U}{d \eta}, U^{\prime \prime}=\frac{d^{2} U}{d \eta^{2}}, \ldots \ldots$.

Step 2: Taking the trial solution for Eq. (4) as:

$$
U(\eta)=\sum_{\mathrm{i}=0}^{\mathrm{n}} a_{i} \mathrm{~F}^{\mathrm{i}}(\eta)=a_{0}+a_{1} \mathrm{~F}(\eta)+a_{2} \mathrm{~F}^{2}(\eta)+\ldots \ldots+a_{n} \mathrm{~F}^{\mathrm{n}}(\eta),
$$

where

$$
F^{\prime}=\alpha F(\eta)+\beta F^{M}(\eta)
$$

where $\quad \alpha \nexists 0, \beta \boxplus 0, M \in R \backslash\{0,1,2\}$, and $F(\eta)$ is Bernoulli differential polynomial. Substituting above relations into Eq.(4), we acquire an equation of polynomial $\Omega(F(\eta)$ ) of $F(\eta)$

$$
\Omega(F(\eta))=\rho_{S} F^{S}(\eta)+\ldots+\rho_{1} F(\eta)+\rho_{0}=0
$$


According to the balance principle, we can get values of and $\mathrm{M}$ and $\mathrm{n}$.

Step 3: Let us assume the coefficients of $\Omega(F(\eta))$ all be zero, we will obtain an algebraic equations system:

$$
\rho_{\mathrm{i}}=0, \mathrm{i}=0, \ldots, \mathrm{s} .
$$

Solving this system, we will determine the values of $a_{0}, \ldots . a_{n}$.

Step 4: When we solve nonlinear Bernoulli differential equation that is Eq. 6, we obtain the following to situations according to $\alpha$ and $\beta$;

$$
\begin{gathered}
F(\eta)=\left[\frac{-\beta}{\alpha}+\frac{E}{e^{\alpha(M-1) \eta}}\right]^{\frac{1}{1-M}}, \alpha \neq \beta, \\
F(\eta)=\left[\frac{(E-1)+(E+1) \tanh \left(\frac{\alpha(1-M) \eta}{2}\right)}{1-\tanh \left(\frac{\alpha(1-M) \eta}{2}\right)}\right]^{\frac{1}{1-M}}, \alpha=\beta, \mathrm{E} \in \mathrm{R} .
\end{gathered}
$$

Using a complete discrimination system for polynomial, we obtain the solutions to Eq.(4) via some computer programming and classify the exact solutions to Eq.(4). For a better comprehension of findings found in this way, we can plot two and three imensional surfaces of solutions by taking into consideration favorable parameter values.

\section{Application of BSEFM}

In this section, it has succesfully applied the BSEFM to the equation for getting some new complex travelling wave solutions. If we consider Eq.(1b), as a simplicity, $[B]=U$, we cowrite following.

$$
U^{\prime}-C U+P U^{2}=0 .
$$

Applying the homogeneous blancing technique between the highest derivative $U^{\prime}$ and the highest nonlinear term $U^{2}$, yields the following relationship among $\mathrm{n}$ and $\mathrm{M}$;

$$
\mathrm{M}=\mathrm{n}+1, \quad \mathrm{n}, \mathrm{M} \in \mathrm{Z}^{+} .
$$

If we take as $n=3$ and $M=4$ in Eq. (5), we can write following equation;

$$
U=a_{\mathrm{o}}+a_{1} F+a_{2} F^{2}+a_{3} F^{3} .
$$

For the first derivation of $U$, we can write following equation;

$$
U^{\prime}=a_{1} \alpha F+a_{1} \beta F^{4}+2 a_{2} \alpha F^{2}+2 a_{2} \beta F^{5}+3 a_{3} \alpha F^{3}+3 a_{3} \beta F^{6},
$$

where $a_{3} \neq 0, \alpha \notin 0, \beta \notin 0$. When we put Eq.(13,14) in Eq.(11), we obtain an algebraic equation including various power degree of $F$. When we consider to zero all coefficients of $F$, we can find an algebraic system. Solving this system with the help of computer programming, we can detect many values of parameters, If we choose the suitable values of such parameters, we detect the following solutions; 
Case 1: For $\alpha \nexists \beta$, it can be considered the following coefficients;

$$
a_{1}=0, a_{2}=0, \alpha=-\frac{P a_{0}}{3}, \beta=-\frac{P a_{3}}{3}, C=P a_{0}
$$

Substituting these coefficients in Eq. (13) along with Eq.(9), we obtain the following exponential function solution for Eq.(1b);

$$
U(t)=a_{\mathrm{o}}+\frac{a_{3}}{e^{p t a_{0} E E-\frac{a_{3}}{a_{0}}}},
$$

where $E E, a_{0}, a_{3}, P$ are real constants with non-zero.

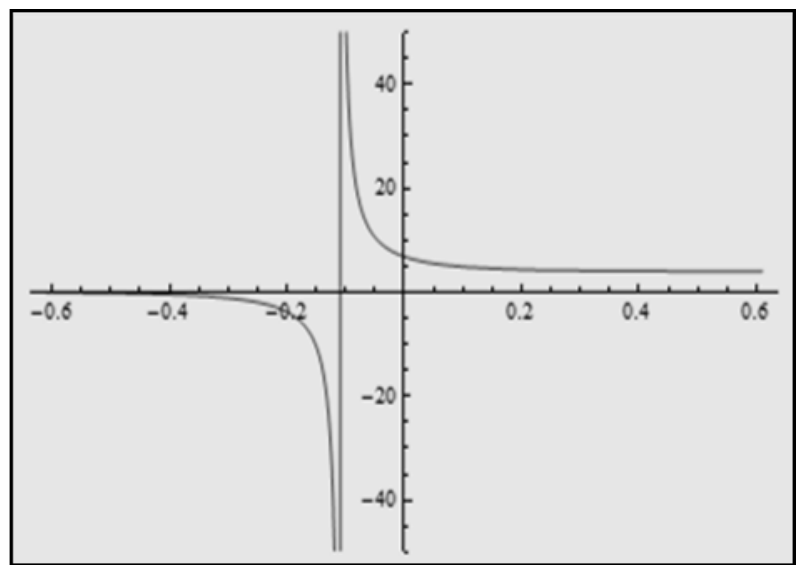

Fig.1. The 2D surface of Eq.(15) under the values of $P=2, E E=3, a_{0}=4, a_{3}=5,-0.6<\mathrm{t}<0.6$

\section{Conclusions}

In this paper, the BSEFM is applied to the nonlinear kinetic model equation. We successfully obtained exponential function solution. We presented the 2D graphs of the obtained solution with the help of some powerful software program.

It has been observed that this solution can be converted into the exist result introduced to the literature when we use exponential function properties.

This result comes from only Case- 1 . Moreover, if we chose as $\mathrm{M}=5$ and $\mathrm{n}=4$.

Where

$$
U=a_{\mathrm{o}}+a_{1} F+a_{2} F^{2}+a_{3} F^{3}+a_{4} F^{4}
$$

$$
F^{\prime}=\alpha F+\beta F^{5}
$$

This will gives more different solution. Finally, if we consider $M=6, n=5$, then, we can write another different solution form as following;

With

$$
U=a_{\mathrm{o}}+a_{1} F+a_{2} F^{2}+a_{3} F^{3}+a_{4} F^{4}+a_{5} F^{5} .
$$

$$
F^{\prime}=\alpha F+\beta F^{6}
$$

The values of $M$ and $n$ is infinitive. This property is belong to the BSEFM. We can 
obtain some other new traveling wave solutions to the nonlinear kinetic model equation. As far as we know, the application of BSEFM to the model considered in this paper has not been submitted to the literature in advance. Therefore, this method is a powerful and efficient mathematical tool that can be used to handle various nonlinear mathematical models.

\section{References}

1. N. Aktaş, Gıda Teknolojisinde Reaksiyon Kinetiği. Atatürk Üniversitesi, Ziraat Fakültesi Ders Yayınları (2008).

2. D.A. Beard, H. Qian, Chemical biophysics: quantitative analysis of cellular systems. Cambridge University Press, Cambridge (2008).

3. M. Earle, R. Earle, Fundamentals of Food Reaction Technology. Leatherhead Food International. Leatherhead, England (2003).

4. J.D. Murray,Mathematical biology, 3rd edn,Springer, Berlin (2003).

5. R. Plonsey, R.C. Barr, Bioelectricity: a quantitative approach, 2nd edn. Kluwer, New York (2000).

6. J. Keener, J. Sneyd, Mathematical physiology, 2nd edn, Springer, New York (2009).

7. Y.O. Devres, M. Pala, Gıda Sanayiinde Matematiksel Modellemenin Önemi ve Uygulama Alanları. GIDA, 18(3) 173-181 (1993).

8. N. Çoksöyler, Gıdalarda Mikroorganizmaların İnaktivasyonunun Modellenmesi. Türkiye 9. Gıda Kongresi, Bolu, 24-26 Mayıs (2006).

9. S.G. Özkal, H. Ercoşkun, Kinetic Modeling of Quality Aspects of Fermented Sausage (Sucuk) During Storage, Kafkas Üniversitesi Veteriner Fakültesi Dergisi, 23(2), 195-200 (2017).

10. F. Düşünceli, M. Şan, B. Bulur, New Exponential and Complex Traveling Wave Solutions to the Konopelchenko-Dubrovsky Model, 3rd International Conference on Computational Mathematics and Engineering Sciences- (CMES2018), Girne/Cyprus, May 04-06 (2018).

11. T.A. Sulaiman, A. Yokus, N. Gulluoglu, H.M. Baskonus, Regarding the Numerical and Stability Analysis of the Sharma-Tosso-Olver Equation, 3rd International Conference on Computational Mathematics and Engineering Sciences- (CMES2018), Girne/Cyprus, May 04-06( 2018).

12. J.W. Cain, Chemical Reaction Kinetics: Mathematical Underpinnings. Molecular Life Sciences,Springer, NewYork (2014).DOI 10.1007/978-1-4614-6436-5_564-1.

13. H. Bulut, G. Yel, H.M. Baskonus, An Application of Improved Bernoulli SubEquation Function Method to The Nonlinear Time-Fractional Burgers Equation. Turk. J. Math. Comput. Sci., 5,1-7 (2016)

14. H. Bulut, S.S. Atas, H.M. Baskonus, Some Novel Exponential and Complex Structural Properties of the Fisher Equation Arising in Mathematical Bioscience. CMES2017,ITM Web of Conferences, 13,01017 (2017).

15. E.Yuce, A. Ö. Tarakçioglu, Attitudes of Computer Engineering Department Students Towards ESP Courses Integrated to Foreign Language Courses: Tunceli University Case, Bilim ve Gençlik Dergisi, 1(1), 47-57(2013). 